\title{
Impact of wastewater treatment plants on microbiological contamination for evaluating the risks of wastewater reuse
}

\author{
Silvia Bonetta ${ }^{1}$, Cristina Pignata ${ }^{2}$, Elisa Gasparro² ${ }^{2}$ Lisa Richiardi², Sara Bonetta ${ }^{2 *}$ (1) and Elisabetta Carraro ${ }^{2}$
}

\begin{abstract}
Background: Wastewater reuse represents a promising alternative source of water supply considering the water scarcity related to climate change. However, if not adequately treated, wastewater represents a source of microbiological health risk. The purpose of this work was to investigate the role of wastewater treatment on microbiological contamination by evaluating the possible risks associated with wastewater effluent reuse, taking into account new EU legislation (2020/741) on minimum requirements for water reuse. E. coli that produce Shiga toxins (STEC) and thermotolerant Campylobacter were monitored using an enrichment step associated with specific PCR, while Salmonella spp. and Legionella were detected with both cultural and molecular methods (PCR and q-PCR, respectively). Culture method was also used for the enumeration of different microbial indicators. The bacteria detection was compared in different wastewater plants with membrane bioreactor (MBR) system or with disinfection step with chlorine dioxide $\left(\mathrm{ClO}_{2}\right)$. Moreover a comparison between molecular and culture methods was discussed.

Results: The results obtained showed good abatement performance for WWTPs equipped with MBR. The high concentrations of E. coli (range between 0.88 and $5.21 \mathrm{Log}$ MPN/100 mL) and contamination by Salmonella spp. in effluent disinfected with $\mathrm{ClO}_{2}$ (17\% of samples) showed the need to control the quality of this effluent. In addition, despite the absence of Legionella spp. with the culture method required by EU regulation, high concentrations of Legionella spp. (range between 2 and $7 \log$ GU/L) and the presence of Leg. pneumophila with qPCR (15\% of samples) highlight the need to carry out further investigations for reuse associated with aerosol formation (e.g. spray irrigation in agriculture).

Conclusions: The results obtained underline that the MBR technology can be suitable for wastewater reuse applications allowing to achieve the requirement proposed by the new European legislation. More attention should be given to wastewater reuse of effluents treated with $\mathrm{ClO}_{2}$. The use of the molecular methods for pathogens detection in wastewater could allow a more precautionary risks estimation associated with reuse. The overall results highlight that an evaluation of the effectiveness of the wastewater treatments is required for the prevention of a possible risk to public health.
\end{abstract}

Keywords: Wastewater reuse, MBR, Disinfection, Legislation, Pathogenic bacteria, Indicator microorganisms, STEC, Legionella pneumophila, Legionella spp.

\footnotetext{
*Correspondence: sara.bonetta@unito.it

2 Department of Public Health and Pediatrics, University of Torino, Via

Santena 5 bis, 10126 Torino, Italy

Full list of author information is available at the end of the article
}

\section{Background}

The availability of freshwater reservoirs is severely influenced by different anthropic activities such as climatic change and urban development [1]. In particular, climate change can affect water necessity for human needs 
in terms of quality and quantity, further exacerbating the situation of water scarcity that already characterises many world areas. Moreover, the growth of the world population will determine in the future the increase in the global demand for water to satisfy domestic, agricultural and industrial needs [2]; in addition, a greater number of urban settlements and human activities will lead to an increase in wastewater production. In this context, wastewater can become the main alternative source of water supply, providing a resource, the availability of which is not subjected to seasonality and does not require additional depletion of groundwater and surface water bodies. However, treated wastewater remains a minor source of water supply: at present, $0.59 \%$ of treated wastewater in the world and $2.4 \%$ in Europe are reused [3].

To ensure that wastewater reuse does not pose a threat to human health, the efficacy of wastewater treatment and the monitoring of effluent quality to prevent and limit the spread of diseases represent the main topics. Recently, European regulation (2020/741) on minimum requirements for water reuse has been adopted with the purpose of facilitating the safe reuse of treated urban wastewater for agricultural irrigation. This EU regulation proposes an approach based on minimum requirements in terms of reference indicators or pathogens and risk management when wastewater is reused for irrigation [4]. The reclaimed water quality requirements for agricultural irrigation according to new EU Regulation (2020/741) are reported in Table 1.

In fact, if not adequately treated, urban wastewater represents a source of microbiological health risk: its direct use in agriculture can lead to the production of contaminated food and to the spread of contamination in the environment through water leaching and runoff [5]. Moreover, the wastewater reuse can pose direct risks to workers or indirect risks to people living near application sites due to aerosolisation. It is known that numerous pathogenic microorganisms with various resistance capabilities towards environmental conditions and wastewater treatments can be transmitted through water reuse. Therefore, it is important to study pathogens that can represent a health risk in wastewater reuse.

Different studies have shown that pathogenic Campylobacter (jejuni and coli), Salmonella spp. and E. coli that produce Shiga toxins (STEC) were observed in treated wastewater [6], highlighting that irrigation with reused water could represent a source of contamination for fruit and vegetables. The Surveillance for Foodborne Diseases Outbreaks-United States annual reports from 2009 to 2015-reported Salmonella and STEC as two of the most common causes of large outbreaks frequently associated with vegetable consumption [7].
Additionally, in the EU, Campylobacter (jejuni and coli), Salmonella (mainly S. Enteritidis serovar) and STEC represent the most frequently reported causative agents of foodborne outbreaks in 2019; different cases of illness caused by Salmonella and STEC are associated with vegetables [8]. Moreover, the raw vegetables are a relevant source of risk for campylobacteriosis for consumers [5].

Wastewater reuse in agriculture may also represent a possible health risk associated with aerosol production. In fact, the irrigation method (e.g. spray irrigation) can affect the dispersion of aerosols containing pathogens such as Legionella, associated with occupational risk. Although it is known that wastewater could represent an important source of Legionella, only a few studies have focused on the occurrence of this bacterium in wastewater treatment systems $[9,10]$. Several outbreaks of Legionnaires' disease have been associated with aerosol production in the biological step of wastewater treatment plants, and aerosols can spread great distances from the treatment site (up to $1.6 \mathrm{~km}$ ) [10]. Both reuse for agricultural and landscape irrigation and for cooling purposes should be considered possible sources of aerosol generation, underlining the importance of Legionella monitoring in wastewater-treated effluents [11]. The occurrence of Legionella was reported in reclaimed wastewater utilised for different purposes (e.g. agricultural use and toilet flushing) in the USA, France and Australia [10].

To improve the microbiological quality of wastewater for reuse purposes, different approaches can be used: it is possible to introduce new technologies in the secondary step of wastewater treatment (e.g. membrane bioreactors, MBRs) or optimise the performance of the final disinfection step of the wastewater treatment plant (e.g. type and amount of disinfectant). The advantages related to MBR use are a small footprint and lower chemical requirements than conventional membrane systems. However, the main disadvantage is the energy consumption largely associated with membrane fouling $[12,13]$. MBRs could be particularly suitable for wastewater reuse applications because this technology seems to show a greater ability to reduce some viruses (e.g. coliphage) or bacterial indicators (e.g. faecal coliforms) with respect to conventional activated sludge processes [13]. Despite these promising results, further investigation is deemed required to gain a more complete understanding, because different factors can influence the MBR performance (e.g. the nominal pore size, membrane integrity, development of a gel/cake layer on membrane surface, the adsorption of pathogens to suspended solids) $[12,13]$. In this context, it is of particular interest to study the abatement against different bacterial pathogens in full-scale wastewater treatment plants. 


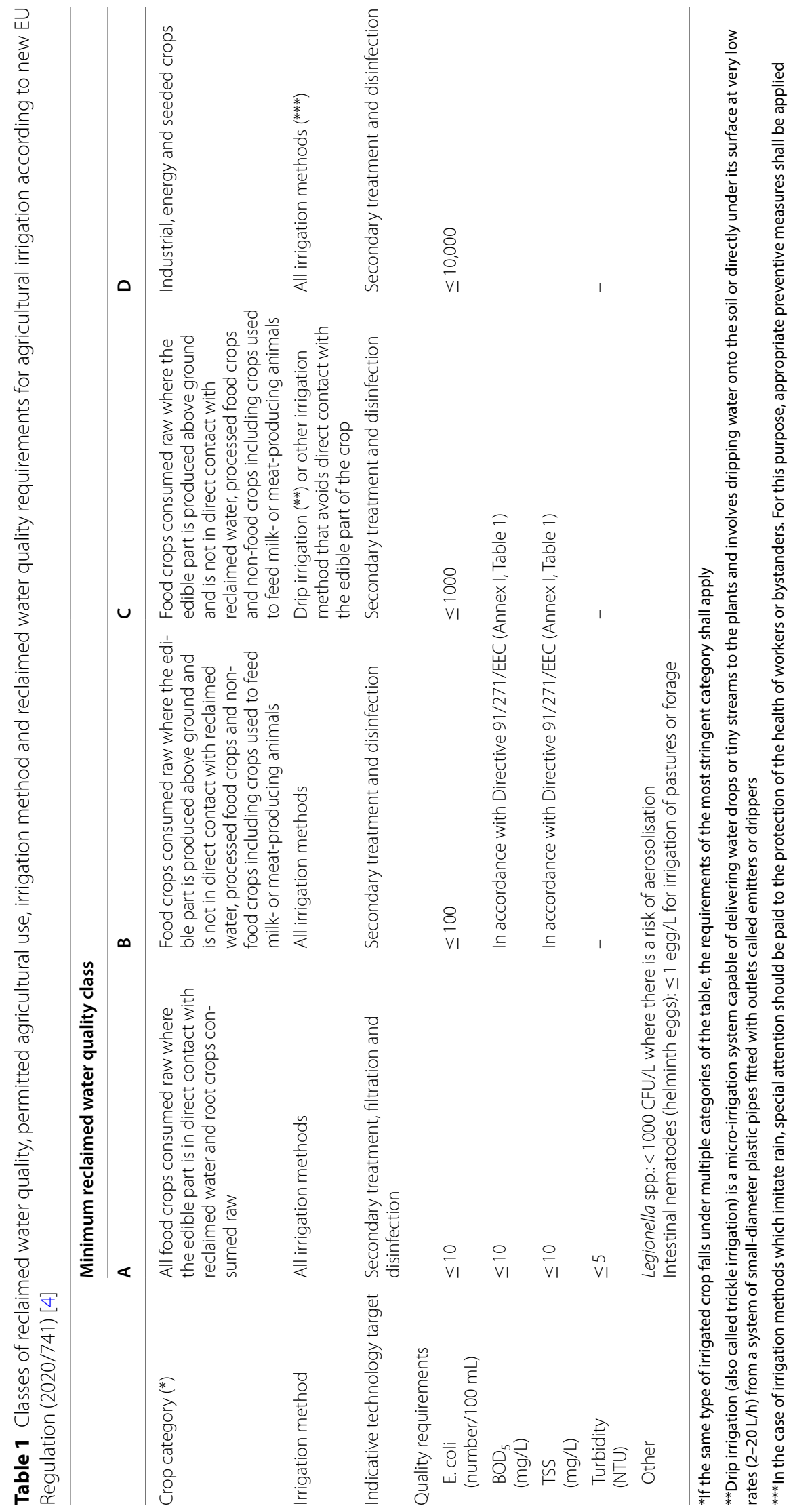


For the tertiary treatment of wastewater before reuse, disinfection can be carried out with chemical substances (e.g. $\mathrm{Cl}, \mathrm{ClO}_{2}$, PAA) or physical treatments (e.g. UV) [14]. Chlorine dioxide $\left(\mathrm{ClO}_{2}\right)$ has several advantages: it is a better bactericide and virucide than sodium hypochlorite and chlorine, in relationship to its greater oxidative capacity [15]. However, physical and chemical characteristics of wastewater (temperature, $\mathrm{pH}$, organic load) can influence the disinfecting capacity of $\mathrm{ClO}_{2}$ and, consequently, the disinfectant dosage required and the contact time. Different studies comparing the removal of bacteria indicators with $\mathrm{ClO}_{2}$ and other tertiary treatments showed that $\mathrm{ClO}_{2}$ is more efficient than peracetic acid (PAA) and UV at high concentration (5 mg/L) [16]. At lower dosage $(2 \mathrm{mg} / \mathrm{L}) \mathrm{ClO}_{2}$ and PAA presented similar abatement against bacterial and viral indicators [15].

The purpose of this study was to evaluate the role of wastewater treatment on microbiological contamination, investigating the possible risks associated with wastewater effluent reuse, with a view to new EU legislation on minimum requirements for water reuse. For this scope, pathogenic bacteria (Salmonella, STEC, thermotolerant Campylobacter, Legionella) and microbial indicators (total coliform, E. coli, enterococci and spores of Clostridium perfringens) were compared in different fullscale municipal wastewater plants equipped with MBR systems or disinfection step with $\mathrm{ClO}_{2}$. Moreover, a comparison between molecular and culture methods for Salmonella and Legionella was discussed.

\section{Materials and methods \\ Sampling}

Samples were collected from three Italian wastewater treatment plants (WWTP1, WWTP2, WWTP3) in seven sampling periods (from January to September 2020). WWTP1 (35,000 population equivalent) and WWTP2 (36,000 population equivalent) employ wastewater pretreatment (screening, sand and oil removal), biological treatment and ultrafiltration with monolithic hollow fibre membranes (MBR) of polyvinylidene fluoride (PVDF) (nominal membrane pore size: $0.04 \mu \mathrm{m}$; trans membrane pressure-TMP (max): $60 \mathrm{kPa}$ ). WWTP3 (168,000 population equivalent) employs wastewater pre-treatment (screening, sand and oil removal), primary settling, oxidation, secondary settling, and disinfection with $\mathrm{ClO}_{2}$ (dose applied $1.2 \mathrm{mg} / \mathrm{L}$; contact time $1 \mathrm{~h}$ ) before effluent discharging. The wastewater influent and the final effluent were sampled in WWTP1 and WWTP2, while in WWTP3, the effluent before and after the final disinfection treatment (final effluent) was monitored. The diagram of wastewater treatment plants and the sampling points is shown in Fig. 1.

\section{Microbial indicators}

All samples were analysed for total coliforms, enterococci, E. coli and Clostridium perfringens spores counts. Quanti-TrayTM 2000 (IDEXX Laboratories, Milan, Italy) was utilised for the quantification of coliforms, enterococci and E. coli, and the results were expressed as Log MPN/100 mL. The enumeration of $C$. perfringens spores was performed using a membrane filtration method according to ISO 14189:2013 [17], and the results were reported as Log CFU/100 mL. All wastewater samples were transported refrigerated and processed within $24 \mathrm{~h}$ of collection.

\section{Pathogens}

The presence/absence of STEC, Salmonella spp. and pathogenic Campylobacter (jejuni and coli) in wastewater samples was carried out using a PCR method with a previously reported protocol [7]. Briefly, samples (influent $=100 \mathrm{~mL}$; effluent $=1 \mathrm{~L}$ ) were concentrated by filtration and enriched in specific media. DNA extraction and purification was carried out with the DNeasy PowerSoil Kit (Qiagen). PCR was conducted as reported in Bonetta et al. [7, 18]. Positive controls were prepared spiking an influent sample, for each sampling period, with high concentration $\left(\sim 10^{6} \mathrm{CFU}\right)$ of E. coli $\mathrm{O} 157: \mathrm{H} 7$ (NCTC129), S. typhimurium (ATCC14028) and Cam. jejuni (ATCC33291).

Legionella detection (spp. and pneumophila) was carried out using a quantitative molecular PCR method as previously described [19]. Briefly, $20 \mathrm{~mL}$ of influent and $250 \mathrm{~mL}$ of different effluents were concentrated by filtration; DNA was extracted from filter using the DNeasy PowerWater Kit (Qiagen) and quantified using commercial kits (iQ-Check Quanti Legionella spp. and Leg. pneumophila-BioRad). Each sample was tested in duplicate and the results were reported as the genome units (GUs) per litre of sample. The detection limit was $2500 \mathrm{GU} / \mathrm{L}$ for influent samples and $200 \mathrm{GU} / \mathrm{L}$ for effluent or predisinfected samples. The quantification limit was 20,000 GU/L for influent samples and $1600 \mathrm{GU} / \mathrm{L}$ for effluent or pre-disinfected samples.

Both Salmonella spp. and Legionella spp. were monitored with culture method in parallel with molecular detection. The culture method described in Bonetta et al. [7] was used for Salmonella spp. and results were expressed as presence/absence. The isolation and identification of Legionella was performed following ISO 11731:2017 [20]. Briefly, the effluents (concentrated by centrifugation) and the influents were analysed untreated or pretreated with heat $\left(50 \mathrm{C}^{\circ}\right.$ for $\left.30 \mathrm{~min}\right)$ and acid ( $\mathrm{pH} 2.2$ for $5 \mathrm{~min}$ ) to reduce the growth of interfering microflora, serially diluted, plated on GVPC agar and 


\section{WWTP1 and WWTP2}
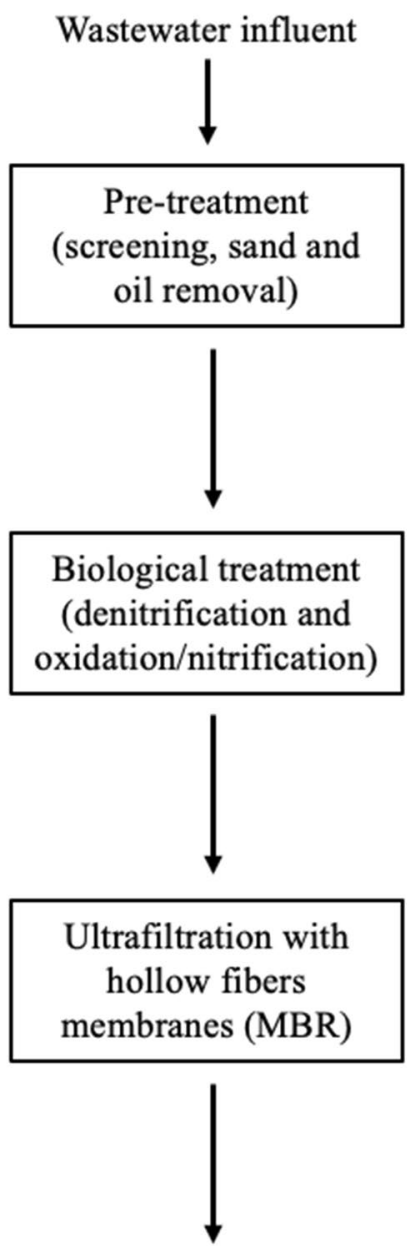

Final effluent
Sampling
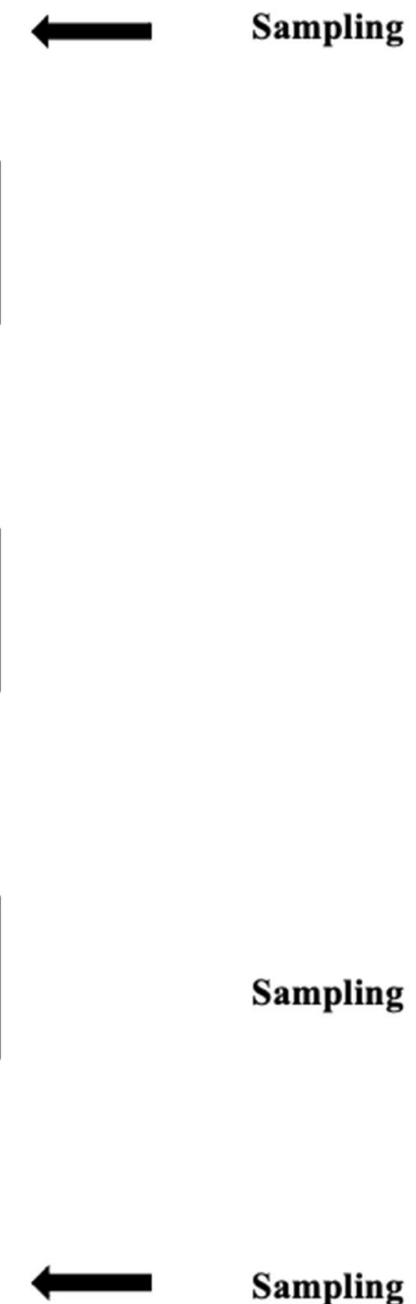

Sampling

Sampling
WWTP3

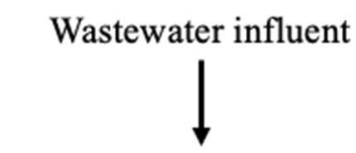

Pre-treatment

(screening, sand and

oil removal)
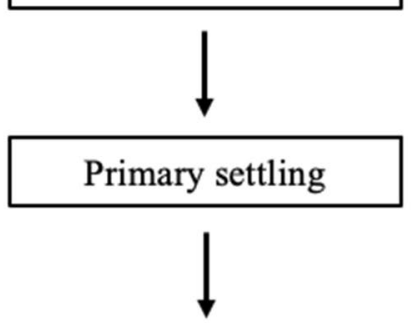

Biological oxidation

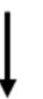

Secondary settling

Disinfection with $\mathrm{ClO}_{2}$

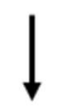

Final effluent

Fig. 1 Diagram of the wastewater treatment plants showing sampling points

incubated for 7-10 days at $37{ }^{\circ} \mathrm{C}$. Suspected colonies were randomly selected for subculture on $\alpha$-BCYE agar and $\alpha$-BCYE agar without L-cysteine. Confirmed colonies were identified using an agglutination test (Legionella latex test; Oxoid). All wastewater samples were transported refrigerated and processed within $24 \mathrm{~h}$ of collection. The results were reported as CFU/L; the detection limits were $2 \times 10^{3}$ and $10^{2} \mathrm{CFU} / \mathrm{L}$ for influents and effluents, respectively. S. typhimurium (ATCC14028) and Leg. pneumophila (ATCC 33152) strains were used as positive control.

\section{Physical and chemical analyses}

Chemical oxygen demand (COD) was determined using the sealed tube method [21]; biochemical oxygen demand
(BOD) was determined by dilution and seeding with suppression of nitrification [22]; and total suspended solids (TSS) was collected by filtration on membrane and gravimetric analysis was performed after filter drying [23]. These parameters were not available for pre-disinfected samples in the WWTP3.

\section{Statistical analyses}

The presence/absence of pathogens and concentration of bacterial indicators and Legionella (Log conversion) were statistically analysed (IBM SPSS Statistics version 26.0 for Windows).

The normal distribution was evaluated using ShapiroWilk test. To analyse the differences in microbial contamination between the influent and effluent samples, 
the effluents collected in the pre- and post-disinfection step and influent samples of WWTP1 and WWTP2 Student's $t$-test was applied. ANOVA and Tukey's post hoc analysis were carried out to study the effect on microbial contamination of the different treatments performed in the three WWTPs. To evaluate the relationship between concentration of indicator bacteria and the occurrence (presence/absence) of Salmonella spp., STEC and Campylobacter (jejuni and coli) in wastewater samples binary logistic regression was carried out. Spearman's correlation was used to evaluate the association between the microbiological and physicochemical parameters in each wastewater plant. Significance was evaluated within $95 \%$ confidence intervals $(p \leq 0.05)$.

\section{Results and discussion Microbial indicators}

The results of the microbial indicator concentrations in all samples investigated are reported in Fig. 2. As observed, the concentrations of $E$. coli, total coliforms, enterococci and spores of $C$. perfringens were similar in the influent samples collected from WWTP1 and WWTP2 ( $t$-test, $p>0.05$ ), highlighting that the microbiological characteristics of the two influents are analogous. By comparing the indicator concentrations in the effluents of the three plants, in general, the counts were higher in WWTP3 than in the other two plants. However, this difference was statistically significant only between WWTP3 and
WWTP2 for all parameters, with the exception of the enterococci count (ANOVA, $p<0.05$ ).

In both WWTP1 and WWTP2, a statistically significant reduction $(t$-test, $P<0.001)$ of all the microbiological parameters investigated was revealed in the effluent with respect to the influent, with a range of abatement of 3-5 Log and 3.5-6 Log for WWTP1 and WWTP2, respectively (Fig. 3). These results showed good abatement performance for both wastewater treatments in which MBRs were used, especially for WWTP2, although no statistically significant differences were observed between the effluents of WWTP1 and WWTP2. This behaviour could be related to the fact that the two WWTPs had MBR with the same characteristics (e.g. kind of membrane, membrane pore size, membrane material, TMP). Bolzonella and collaborators [24] also reported similar abatement values by MBR. However, other studies highlighted a higher efficiency of this treatment on domestic and industrial wastewaters, allowing reduction values up to $7 \log$ for coliforms and E. coli and $5 \log$ for C. perfringens $[25,26]$. Moreover, a further improvement of the microbial reduction was observed by adding a disinfection step with hypochlorite and/or UV, reaching a total reduction of E. coli and enterococci and a further abatement ( 1Log) of total coliforms [27, 28].

In the WWTP3, the mean reduction of microbial indicators range from 0.63 to 1.44 with values $>1 \mathrm{Log}$ for E. coli and Enterococci (mean concentration of $\mathrm{ClO}_{2}: 1.2 \mathrm{mg} / \mathrm{L}$ ) (Fig. 3). Similar efficiency of the disinfection step with $\mathrm{ClO}_{2}$ was observed by De Luca and

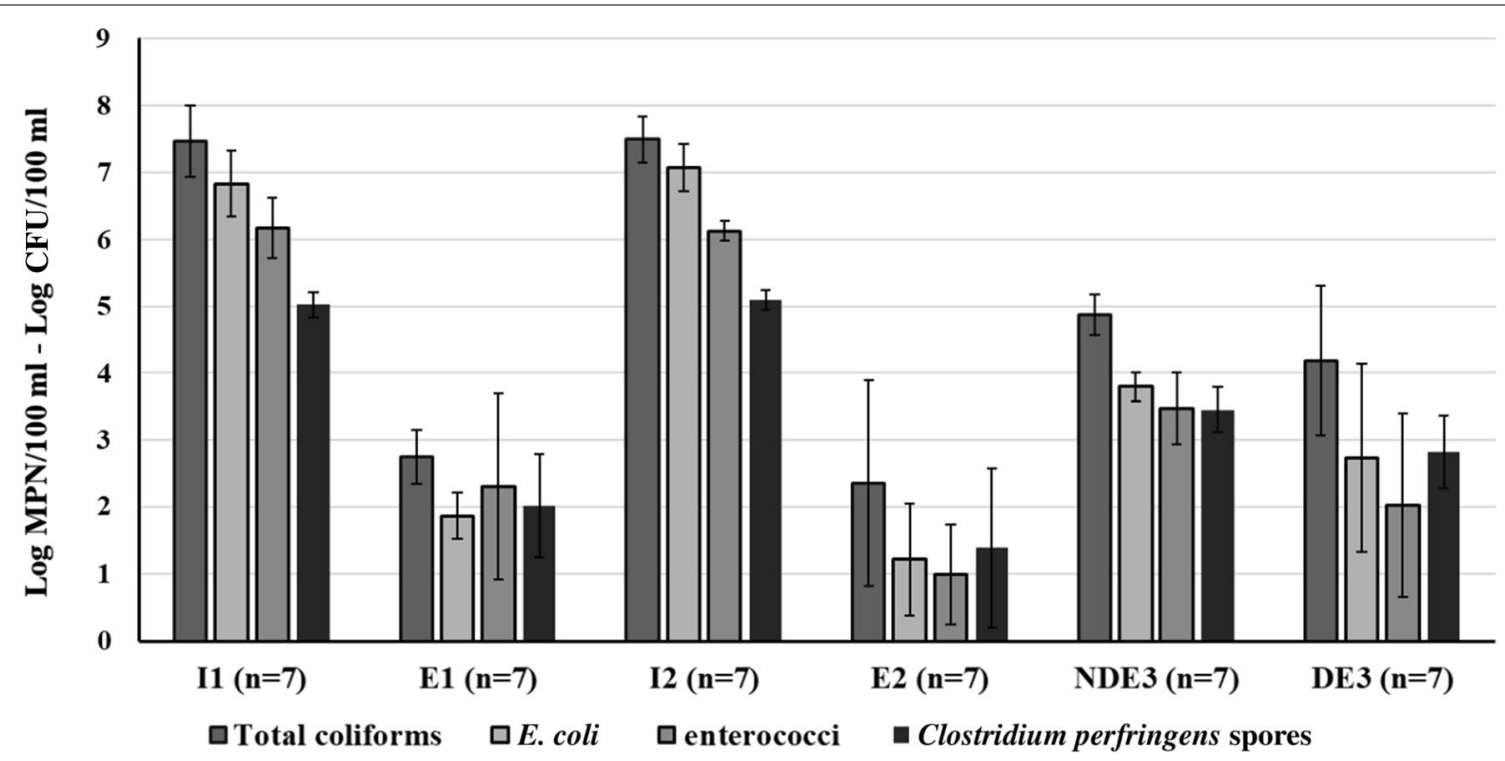

Fig. 2 Mean concentration ( \pm standard deviation) (log CFU/100 mL or Log MPN/100 mL) of microbial indicators in WWTP samples (I: influent; E: effluent; NDE: pre-disinfected effluent; DE: post-disinfected effluent; 1:WWTP1; 2:WWTP2; 3:WWTP3) 


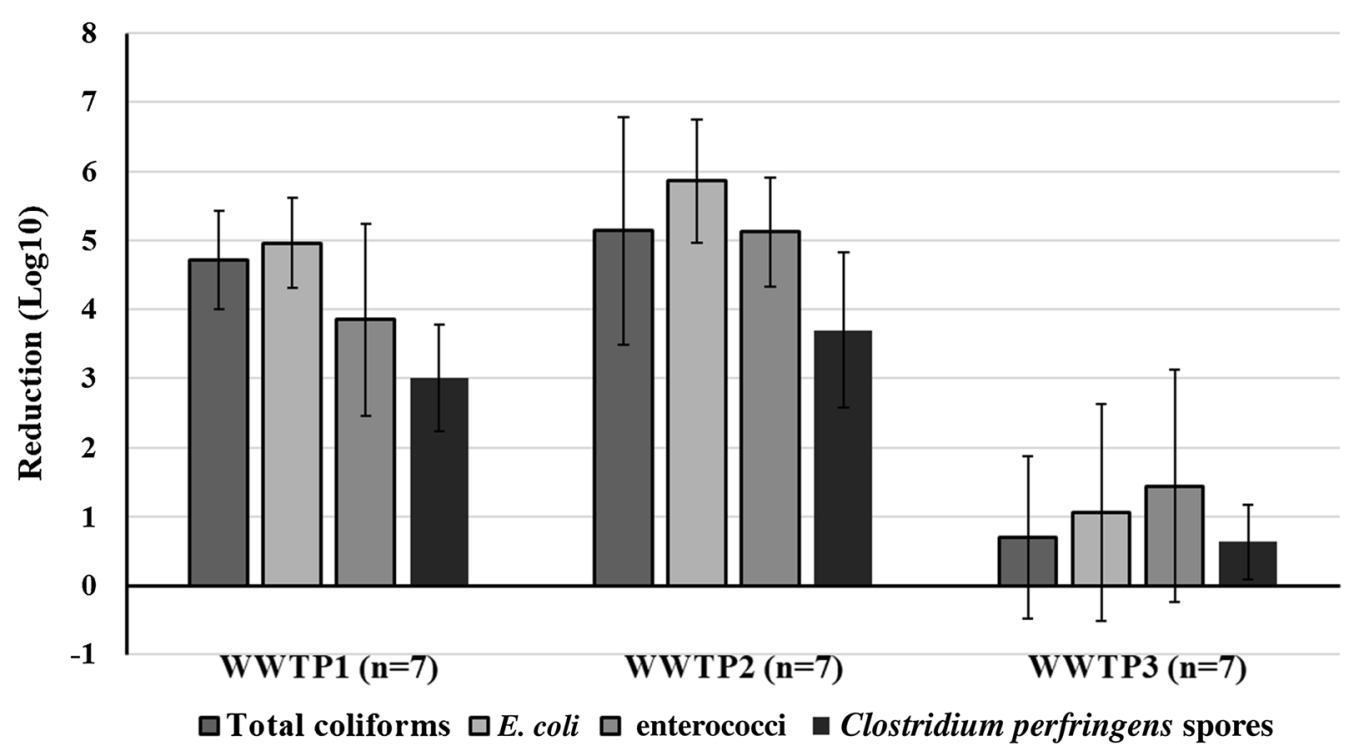

Fig. 3 Mean reduction ( \pm standard deviation) (Log CFU/100 mL or Log MPN/100 mL) of microbial indicators in the WWTPs

collaborators in a WWTP that operated with a $\mathrm{ClO}_{2}$ dose of $1.5 \mathrm{mg} / \mathrm{L}$. In the same study a better performance was obtained with $2 \mathrm{mg} / \mathrm{L}$ of $\mathrm{ClO}_{2}$ applied dose [15]. Moreover, other studies reported higher values of microbial abatement related to final disinfection with $\mathrm{ClO}_{2}$ (range 2-5 Log for total coliforms and E. coli). However these results were obtained combining the $\mathrm{ClO}_{2}$ disinfection step with a pre-treatment phase (e.g. filtration or adding flocculant agent) [16] or using higher doses of $\mathrm{ClO}_{2}$ [29].

In the current Italian legislation for wastewater reuse, the regulatory reference limit for $E$. coli concentration is $10 \mathrm{CFU} / 100 \mathrm{~mL}$ (for at least $80 \%$ of samples) [30]. No samples of the effluent collected in the WWPT1 comply with this limit, underlining that, in these conditions, this treated wastewater could not be reused for irrigation, industrial or civil purposes (Additional file 1: Fig. S1). Forty-three percent of effluent samples (3/7) of WWTP2 presented values below this limit, highlighting a greater potential of the effluent of this WWTP for reuse. Since both WWTPs are equipped with MBR technology, generally suitable in the case of wastewater reuse, a thorough and careful analysis of the process conditions and the filtration efficiency of the membranes would allow us to identify useful changes to obtain a higher microbiological quality of the wastewater. In addition to membrane characteristics other factors that can affect pathogen removal by membranes should be considered and managed. In fact the development of a gel/cake layer on membrane surface, due to the accumulation of biomaterials, can modify the pathogens removal. The adsorption of pathogens to suspended solids, which depends on the characteristics of the influent water (e.g. pH, concentration of $\mathrm{NH}_{3}$ or $\mathrm{NaCl}$ ), can also affect membranes removal capacity. Membrane integrity is another important factor, because irregularities due to physical and chemical damage can result in a loss of pathogen removal efficiency [12, 13]. Moreover, as reported in other studies [27, 28], the application of an adequate final disinfection of the effluent could contribute to a further microbial reduction. However, this possibility should be carefully evaluated from an economic perspective, considering that the same MBR systems already involve higher energy and management costs than traditional activated sludge treatment.

The analysis of the results obtained in the samples from WWTP3 effluents demonstrate that only one sample complied within the limit value for E. coli, while the others showed concentrations higher than $2 \log$ MPN/100 mL and up to $5 \log$ MPN/100 mL, highlighting the need for a more efficient tertiary treatment (e.g. higher $\mathrm{ClO}_{2}$ dose) or, in some cases, the requirement to secondary treatment improvement (e.g. MBR technologies).

The new EU Regulation [4] for wastewater reuse establishes different limit values for $E$. coli concentration according to the specific use (Table 1). Referring to this regulation, the effluent of all WWTPs, except a sample of WWTP3, complied with both the limit values for "industrial, energy and seeded crop use" $(\leq 10,000 \mathrm{CFU} / 100 \mathrm{~mL}$, class D) and for "drip irrigation of food crops consumed raw (with no direct contact of edible part of vegetable with reclaimed water), processed food crops and non-food crops" $(\leq 1000 \mathrm{CFU} / 100 \mathrm{~mL}$, 
class C). Moreover, 71\% (5/7), 86\% (6/7) and 14\% (1/6) of all effluents analysed showed $E$. coli values lower than $100 \mathrm{CFU} / 100 \mathrm{~mL}$ (Class B), a limit established for water reused for the same food crops previously reported but "using all irrigation method". Only a few samples complied with the limit prescribed for the irrigation of all food crops consumed raw (with direct contact of edible part of vegetable with reclaimed water) and root crops consumed raw ( $\leq 10 \mathrm{CFU} / 100 \mathrm{~mL}$, class A).

\section{Pathogens}

Table 2 shows the results of Salmonella spp., STEC and Campylobacter (jejuni and coli) detection carried out in the three wastewater plants monitored. The presence of Salmonella spp. was reported in 100\% (7/7) and 86\% (6/7) of WWTP1 influents using molecular and cultural methods, respectively. In the WWTP2 Salmonella spp. was detected in $71 \%(5 / 7)$ of influent samples with the molecular method, while a sole sample (14\%) was positive with the culture method. Additionally, Cataldo and collaborators [31] reported a similar percentage of contamination in the influent samples (from 100 to $25 \%$ ). Fifty percent of pre-disinfected samples (3/6) collected in the WWTP3 were contaminated by Salmonella spp. with both methods. These results highlight a greater sensitivity of the molecular method over the culture method. This is probably related to the difficulty of isolating $\mathrm{Sal}$ monella on culture media due to the presence of interfering microflora, as previously reported [32] or to the use of an enrichment step for the molecular method that can aid the recovery of injured, stressed or lag-phase bacterial cells [33]. Moreover, Salmonella spp. was not detected in the effluents of WWTP1 and WWTP2 using either method, highlighting the efficacy of MBR in Salmonella abatement. In contrast, in 17\% (1/6) of the WWTP3 disinfected samples, Salmonella spp. contamination was observed with both methods underlining that the disinfection step, although showing a reduction in positive samples, was not able to remove the contamination completely. No relationship between Salmonella spp. presence and microbial indicators was observed with binary logistic regression $(p>0.05)$; this finding suggests that the microbial parameters analysed are probably not reliable indicators of the presence of this pathogenic bacterium $[6,34]$.

Italian legislation for wastewater reuse in agriculture requires the absence of Salmonella spp. in $100 \%$ of effluent analysed with the culture method. All effluents of WWTP1 and WWTP2 complied with this limit, and therefore, on the basis of these parameters and excluding high counts for $E$. coli, they could potentially be utilised for reuse purposes. Additionally, in the case of the WWTP3, considering the presence of Salmonella spp. in one sample in addition to the high counts of E. coli, further investigations on the efficiency of the disinfection treatment is necessary to improve microbial reduction and obtain the necessary requirements for the reuse of wastewater.

However, considering Salmonella spp. contamination, it is important to emphasise that in the new EU regulation $(2020 / 741)$ on minimum requirements for water reuse [4], this parameter was deleted from the water quality requirements (Table 1 ); therefore, with reference to this regulation, the WWTP3 effluent could also be reused in agriculture.

As reported in Table 2, E. coli O157:H7, Shiga-like toxin (I and II) and Campylobacter (jejuni and coli) were never found in the samples analysed (influents, effluents, pre- and post-disinfection samples). Since the spread of these microorganisms in wastewater influents can reflect the local epidemiological situation and the presence of contamination sources (e.g. livestock production, food industries and slaughterhouses) [35], the absence of these bacteria could be related to a low circulation of these pathogens in the local population. The absence of STEC and pathogenic Campylobacter (jejuni and coli) in wastewater samples was also reported in other studies $[6,32$, 36].

The presence of Legionella pneumophila sg1 was only observed with the culture method in a sole sample of the WWTP1 influent $(6.3 \log$ CFU/L), and in the same sampling, the effluent was contaminated by Legionella spp. (3 Log CFU/L). Mosteo et al. [37] also showed low contamination by Legionella spp. in wastewater samples using culture method. Additionally, molecular analysis with qPCR reported the occurrence of Legionella spp. in all samples (influents, effluents, pre- and post-disinfection samples) collected in the three plants (Fig. 4) with a range of concentrations between 5.1 and 7.2 $\log \mathrm{GU} / \mathrm{L}$. Leg. pneumophila was detected in $86 \%$ and $57 \%$ of the WWTP1 and WWTP2 influents, respectively, and in all pre-disinfected samples of WWTP3. In contrast, among effluent samples, only some of the WWTP3 samples were contaminated by Leg. pneumophila (50\% of disinfected samples). The statistical analyses confirmed the higher values of Legionella spp. and Leg. pneumophila concentrations in effluents of WWTP3 with respect to WWTP1 and WWTP2 (ANOVA, $p<0.05$ ). It is important to highlight that the Leg. pneumophila concentrations monitored in all samples were very low or lower than the limit of quantification (LOQ), as reported in other studies [38].

For WWTP1 and WWTP2, a significant reduction in Legionella spp. and Leg. pneumophila contamination was obtained with MBR wastewater treatment (range 1.8-2 Log for Legionella spp. and 2.2-3 Log for Leg. pneumophila) $(t$-test, $p<0.001)$. In contrast, this trend was 
Table 2 Detection of Salmonella spp., E. coli O157:H7, E. coli virulence genes and Campylobacter (spp., C. coli, and C. jejuni) in full-scale WWTPS

\begin{tabular}{|c|c|c|c|c|c|c|c|c|c|c|c|c|}
\hline \multirow[t]{2}{*}{ Plant } & \multirow[t]{2}{*}{ Sample } & \multirow[t]{2}{*}{ Sampling } & \multirow{2}{*}{$\begin{array}{l}\text { Salmonella } \\
\text { invA }\end{array}$} & \multicolumn{5}{|c|}{ E. coli 0157:H7 } & \multicolumn{3}{|c|}{ Campylobacter } & \multirow{2}{*}{$\begin{array}{l}\text { Salmonella } \\
\text { Culture method }\end{array}$} \\
\hline & & & & 0157 & H7 & Intimin & SLT-I & SLT-II & Genus & C. jejuni & C. coli & \\
\hline \multirow[t]{14}{*}{ WWTP 1} & I & 1 & + & - & - & - & - & - & - & - & - & + \\
\hline & $E$ & 1 & - & - & + & - & - & - & - & - & - & - \\
\hline & I & 2 & + & - & + & - & - & - & - & - & - & + \\
\hline & $E$ & 2 & - & - & - & - & - & - & - & - & - & - \\
\hline & 1 & 3 & + & - & + & - & - & - & - & - & - & + \\
\hline & $E$ & 3 & - & - & - & - & - & - & - & - & - & - \\
\hline & 1 & 4 & + & - & + & - & - & - & - & - & - & + \\
\hline & $E$ & 4 & - & - & - & - & - & - & - & - & - & - \\
\hline & 1 & 5 & + & - & - & - & - & - & - & - & - & + \\
\hline & $E$ & 5 & - & - & - & - & - & - & - & - & - & - \\
\hline & I & 6 & + & - & - & - & - & - & - & - & - & - \\
\hline & $E$ & 6 & - & - & - & - & - & - & - & - & - & - \\
\hline & 1 & 7 & + & - & - & - & - & - & - & - & - & + \\
\hline & $\mathrm{E}$ & 7 & - & - & - & - & - & - & - & - & - & - \\
\hline \multirow[t]{14}{*}{ WWTP 2} & I & 1 & + & - & + & - & - & - & - & - & - & + \\
\hline & $E$ & 1 & - & - & + & - & - & - & - & - & - & - \\
\hline & 1 & 2 & + & - & + & - & - & - & - & - & - & - \\
\hline & $E$ & 2 & - & - & + & - & - & - & - & - & - & - \\
\hline & I & 3 & - & - & + & - & - & - & - & - & - & - \\
\hline & $E$ & 3 & - & - & - & - & - & - & - & - & - & - \\
\hline & 1 & 4 & + & - & - & - & - & - & - & - & - & - \\
\hline & $\mathrm{E}$ & 4 & - & - & - & - & - & - & - & - & - & - \\
\hline & I & 5 & + & - & - & - & - & - & - & - & - & - \\
\hline & $E$ & 5 & - & - & - & - & - & - & - & - & - & - \\
\hline & 1 & 6 & + & - & + & - & - & - & - & - & - & - \\
\hline & $\mathrm{E}$ & 6 & - & - & + & - & - & - & - & - & - & - \\
\hline & 1 & 7 & - & - & - & - & - & - & - & - & - & - \\
\hline & $E$ & 7 & - & - & - & - & - & - & - & - & - & - \\
\hline \multirow[t]{12}{*}{ WWTP 3} & $\mathrm{NDE}$ & 2 & - & - & + & - & - & - & - & - & - & - \\
\hline & $\mathrm{DE}$ & 2 & - & - & + & - & - & - & - & - & - & - \\
\hline & $\mathrm{NDE}$ & 3 & - & - & + & - & - & - & - & - & - & - \\
\hline & $\mathrm{DE}$ & 3 & - & - & - & - & - & - & - & - & - & - \\
\hline & NDE & 4 & + & - & - & - & - & - & - & - & - & + \\
\hline & $\mathrm{DE}$ & 4 & - & - & - & - & - & - & - & - & - & - \\
\hline & $\mathrm{NDE}$ & 5 & - & - & + & - & - & - & - & - & - & - \\
\hline & $\mathrm{DE}$ & 5 & - & - & - & - & - & - & - & - & - & - \\
\hline & $\mathrm{NDE}$ & 6 & + & - & - & - & - & - & - & - & - & + \\
\hline & $\mathrm{DE}$ & 6 & + & - & - & - & - & - & - & - & - & + \\
\hline & $\mathrm{NDE}$ & 7 & + & - & - & - & - & - & - & - & - & + \\
\hline & $\mathrm{DE}$ & 7 & - & - & - & - & - & - & - & - & - & - \\
\hline
\end{tabular}

I influent, $E$ effluent, $N D E$ pre-disinfected effluent, $D E$ post-disinfected effluent, + positive, - negative

not encountered in WWTP3, showing that the reduction obtained with the disinfection step with $\mathrm{ClO}_{2}$ was not relevant. It is important to note that in different studies conducted in WWTPs using different biological processes (including chlorination treatment), the abundance of Legionella was similar or higher in treated wastewater than in influent even at concentrations of chlorine higher $(2-3 \mathrm{mg} / \mathrm{L})$ than those used in this study. 


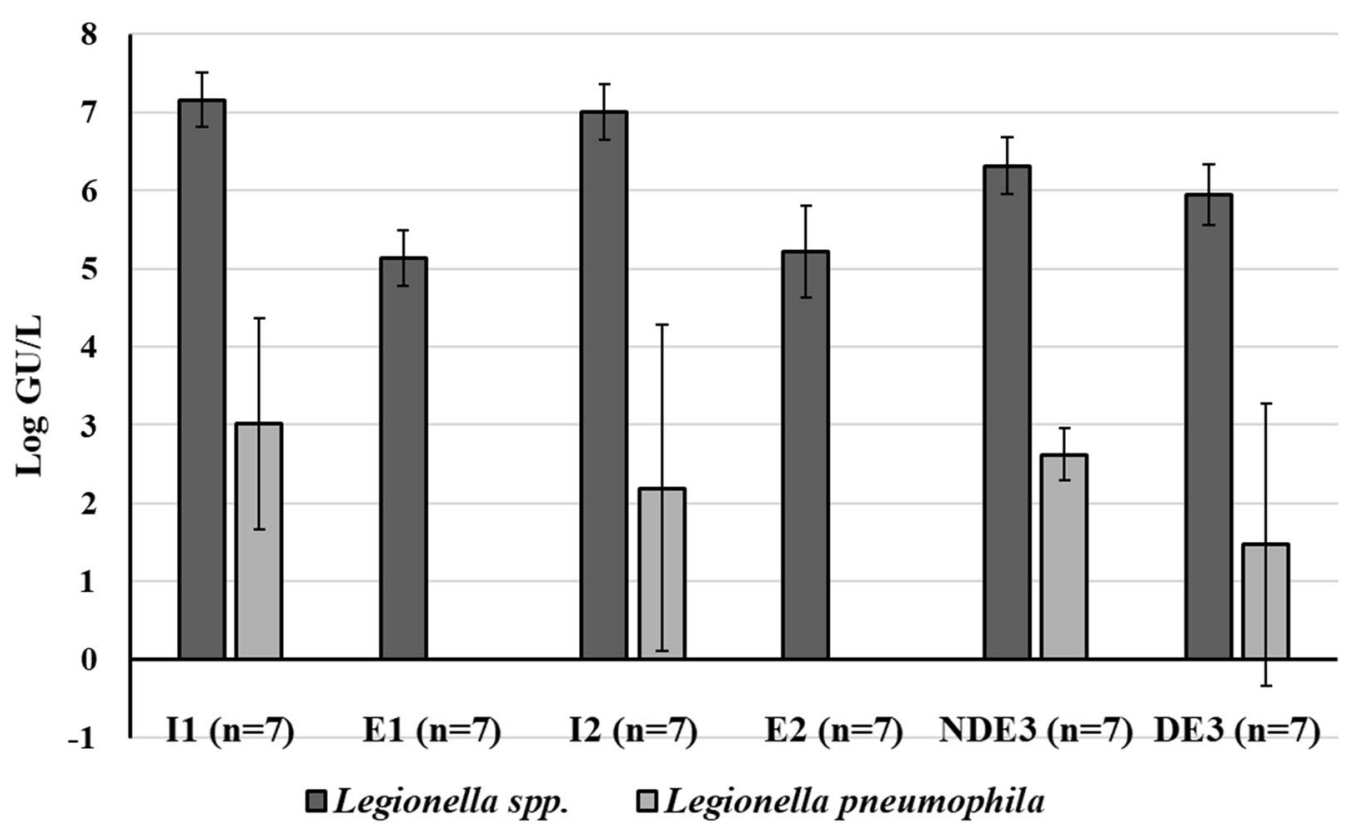

Fig. 4 Mean concentration ( \pm standard deviation) (Log GU/L) of Legionella spp. and Leg. pneumophila in WWTP samples (I: influent; E: effluent; NDE: pre-disinfected effluent; DE: post-disinfected effluent; 1:WWTP1; 2: WWTP2; 3: WWTP3)

This fact confirms that Legionella can survive within the different steps of wastewater treatment because this bacterium is able to grow within protozoa or biofilms [10, 39]. Then, the significant reduction obtained in WWTP1 and WWTP2 investigated in this study highlights that the MBR treatment and the operational parameters used allow to control of Legionella spp. contamination, as was also observed for Salmonella spp.

As reported above, lower Legionella contamination was observed with culture than with molecular methods in the monitored samples. This difference can be attributed to several limitations of the culture method, including the presence of abundant and/or competitive flora, the pre-treatment conditions that could inhibit Legionella growth, and the inability of this technique to detect viable but non-culturable forms (VBNCs) [10]. In fact, in wastewater samples investigated high level of interfering microflora was observed; the plates reading of untreated samples was difficult and heat or acid pre-treatment of samples was often used. The underestimation of Legionella occurrence with the culture method in wastewater samples has been reported in other studies $[9,40]$. On the other hand, the qPCR can instead overestimate health risks since it can also detect dead or damaged microorganisms and this deserves particular attention especially for samples that are subjected to treatments. Other aspects should be considered for the application of the molecular method in wastewater samples: despite the rapidity in the response times of the analysis, the cost of materials and equipment are high; the PCR inhibitors can be present in the samples, then appropriate internal controls should be used; moreover, there is currently non consensus on how qPCR results should be translated into the quantitative limits based on culture reported in legislation. In fact, despite its disadvantages, the culture method actually represents the gold standard to quantify viable and culturable Legionella. Additionally, in the new EU regulation for wastewater reuse, Legionella detection with the culture method was added as a water quality parameter (Legionella spp.: $<1000 \mathrm{CFU} / \mathrm{L}$ ) when a risk of aerosol formation is supposed (Table 1). Referring to this limit, all effluents analysed in this study comply with EU new regulations; however, the high concentration of Legionella spp. and the presence of Leg. pneumophila in the WWTP samples analysed with qPCR underlines the need to carry out further investigation when the reuse of these effluents in agriculture is purposed.

\section{Physical and chemical analyses}

The physicochemical characteristics of the wastewater samples are shown in Fig. 5 (Additional file 1: Table S1). All values measured for BOD and almost all for TSS comply with the limits reported in the new EU regulation for reclaimed water quality class A, except for two effluents that have the TSS values required for reclaimed water quality class B (Table 1 ). A significant correlation was observed between microbiological parameters (total coliforms, E. coli, enterococci, C. perfringens spores, 


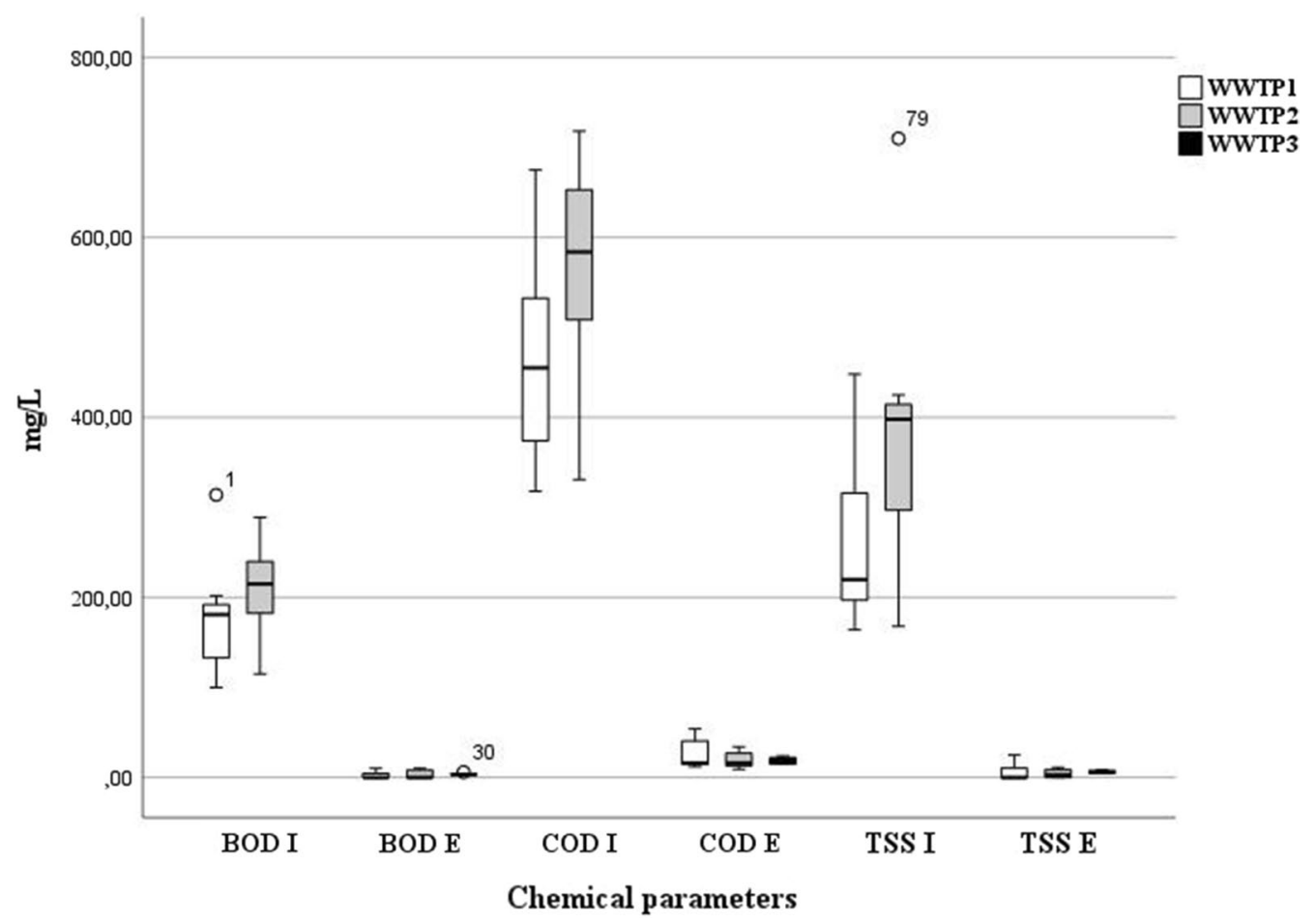

Fig. 5 Box plot of the chemical parameters analysed in WWTP samples (I: influent; E: effluent)

Legionella spp. and Leg. pneumophila) and physicochemical characteristics for WWTP1 and WWTP2 (Spearman correlation coefficient) (Additional file 1: Table S2), highlighting the possibility to use these parameters to support the wastewater quality evaluation and to evaluate the risk of Legionella occurrence in wastewater. It is possible to hypothesise that the physicochemical parameters monitored (TSS, BOD and COD) could be used as surrogates of microbiological indicators fate because the good correlation between parameters allows a good prediction of wastewater quality considering the reuse purpose. A positive correlation between Legionella load and COD was previously reported by Caicedo et al. [9]. The relationship between the removal of indicators and the removal of physicochemical parameters was found by Mailler et al. [41] in different wastewater samples monitored in Paris.

In contrast, no relationship was observed between the microbiological indicators and the physicochemical parameters of the WWTP3 samples, probably due to the limited number of analysed samples.

This study has various strengths: (a) it was performed in full-scale wastewater treatment plants supplied with a promising technology for the production of wastewater that can be reused in agriculture (MBR technology) or with a technology frequently used for wastewater disinfection $\left(\mathrm{ClO}_{2}\right)$; (b) different indicators and pathogens were investigated at the same time to evaluate the possible microbiological risk associated to the reuse purpose; (c) cultural and molecular methods were used for Salmonella spp. and Legionella to compare the results evaluating the usefulness in the monitoring programmes.

This study has also some limits: (a) the study have considered $3 \mathrm{WWTP}_{\mathrm{S}}$ with specific characteristics (e.g. MBR pore size, $\mathrm{ClO}_{2}$ dose), then it could be interesting to carry out further investigation considering WWTPs equipped with others MBR system or using a disinfection step improved (e.g. higher $\mathrm{ClO}_{2}$ dose, adding of a pre-treatment) to achieve the requirement for wastewater reuse purpose; (b) the study mainly regarded bacterial contamination, but it could be interesting keeping virological risk associated to the wastewater reuse; (c) in order to study the risk associated to wastewater reuse the microbiological quality of agricultural products cultivated using treated wastewater could be also considered; (d) the use of qPCR with photoactivatable DNA intercalators (e.g. EMA or PMA) could allow to distinguish viable from dead cells improving the exposure risk evaluation to Legionella. 


\section{Conclusions}

The results obtained underline that the MBR technology can be suitable for wastewater reuse applications allowing to achieve the requirement proposed by the new European legislation. The slight difference between the performance of WWTP1 and WWTP2 confirms the importance of studying the optimal operative conditions of the process. More attention should be given to wastewater reuse of effluents treated with $\mathrm{ClO}_{2}$. An improved tertiary treatment (e.g. higher $\mathrm{ClO}_{2}$ dose) could increase the performance.

The comparison between the results obtained with molecular and culture methods confirmed the greater sensitivity of the molecular method mainly associated to the presence of interfering microflora in wastewater samples. Although it is well known that qPCR for Legionella detection can overestimate the contamination level, its use could allow a more precautionary risks estimation. This is particularly important considering that aerosol formation from wastewater contaminated by Legionella could represent an occupational health risk associated with reuse.

The overall results highlight the importance to evaluate the effectiveness of wastewater treatments with the purpose of agricultural reuse. In this context, the improvement of the treatment system, when necessary, is crucial for the prevention of a possible risk to public health. This activity is also important considering the approach to risk management reported in the EU regulation that comprises assessing risks in a proactive way. That is in order to guarantee that wastewater reuse is safely and managed with aim to prevent the risks for the environment, human or animal health.

\section{Abbreviations}

STEC: Shiga toxin-producing E. coli; MBR: Membrane bioreactor; EU: European Union; qPCR: Quantitative polymerase chain reaction; WWTP: Wastewater treatment plant; MPN: Most probable number; ISO: International Organization for Standardization; CFU: Colony forming unit; GU: Genome unit; COD: Chemical oxygen demand; BOD: Biochemical oxygen demand; TSS: Total suspended solids; ANOVA: Analysis of variance; VBNC: Viable but not culturable.

\section{Supplementary Information}

The online version contains supplementary material available at https://doi. org/10.1186/s12302-022-00597-0.

Additional file 1: Figure S1. E. coli concentration (Log MPN/100 mL) in WWTP effluent (E: effluent; DE: post-disinfected effluent; 1: WWTP1; 2 : WWTP2; 3: WWTP3. Table S1. Results of physical and chemical analyses in the different WWTP samples. Table S2. Results of Spearman's correlation between microbiological parameters and physicochemical parameters in the full-scale WWTPs.

\section{Acknowledgements}

The authors thank the collaboration with the IRETI staff that provided excellent logistical support. This study was supported by the AMGA Foundation, of IREN S.p.A group.

\section{Authors' contributions}

SiB: conceptualisation, methodology, investigation, formal analysis, writingoriginal draft; CP: conceptualisation, investigation, writing - review and editing; EG, LR: investigation, data curation; SaB: conceptualisation, investigation, formal analysis, writing — original draft; EC: conceptualisation, methodology, writing — review and editing, project administration, funding acquisition. All authors read and approved the final manuscript.

Funding

Not applicable.

\section{Availability of data and materials}

The data sets used in this study are available from the corresponding author on reasonable request.

\section{Declarations}

Ethic approval and consent to participate

Not applicable.

Consent for publication

Not applicable.

\section{Competing interests}

There are no conflicts to declare.

\section{Author details}

${ }^{1}$ Department of Life Sciences and Systems Biology, University of Torino, Via Accademia Albertina 13, 10123, Torino, Italy. ${ }^{2}$ Department of Public Health and Pediatrics, University of Torino, Via Santena 5 bis, 10126 Torino, Italy.

Received: 15 November 2021 Accepted: 4 February 2022

Published online: 05 March 2022

\section{References}

1. UNESCO (2020) UN-Water, 2020: United Nations World Water Development Report 2020: water and climate change. UNESCO, Paris

2. L. Alcalde Sanz, B (2014) Gawlik, Water Reuse in Europe - Relevant guidelines, needs for and barriers to innovation. EUR 26947. Luxembourg (Luxembourg): Publications Office of the European Union. JRC92582

3. EU 2016. EU-level instruments on water reuse. Final report to support the Commission's Impact Assessment. Prepared by Amec Foster Wheeler Environment \& Infrastructure UK Ltd, IEEP, ACTeon, IMDEA and NTUA. Luxembourg: Publications Office of the European Union, 2016. ISBN 978-92-79-62616-6

4. EU 2020. REGULATION (EU) 2020/741 OF THE EUROPEAN PARLIAMENT AND OF THE COUNCIL of 25 May 2020 on minimum requirements for water reuse

5. Farhadkhani M, Nikaeen M, Hadi M, Gholipour S, G, (2020) Yadegarfar, Campylobacter risk for the consumers of wastewater-irrigated vegetable based on field experiments. Chemosphere 251:126408

6. Bonetta Si, Pignata C, Lorenzi E, De Ceglia M, Meucci L, Sa Bonetta G, Gilli G, Carraro E (2016) Detection of pathogenic Campylobacter, E. coli O157:H7 and Salmonella spp. in wastewater by PCR assay. Environ Sci Pollut Res 23:15302-15309

7. Dewey-Mattia D, Manikonda K, Hall AJ, Wise ME, Crowe SJ (2018) Surveillance for Foodborne Disease Outbreaks_United States, 2009-2015. MMWR Surveill Summ 67:1-5

8. EFSA and ECDC (European Food Safety Authority and European Centre for Disease Prevention and Control) (2021) The European Union One Health 2019 Zoonoses report. EFSA J 19(2):6406-7286 
9. Caicedo C, Beutel S, Scheper T, Rosenwinkel KH, Nogueira R (2016) Occurrence of Legionella in wastewater treatment plants linked to wastewater characteristics. Environ Sci Pollut Res Int 23:16873-16881

10. Caicedo C, Rosenwinkel KH, Exner M, Verstraete W, Suchenwirth $R$, Hartemann P, Nogueira R (2019) Legionella occurrence in municipal and industrial wastewater treatment plants and risks of reclaimed wastewater reuse: review. Water Res 149:21-34

11. Hamilton KA, Hamilton MT, Johnson W, Jjemba P, Bukhari Z, LeChevallier M, Haas CN (2018) Health risks from exposure to Legionella in reclaimed water aerosols: toilet flushing, spray irrigation, and cooling towers. Water Res 134:261-279

12. M.E. Verbyla, O. Rousselot, Membrane Bioreactors. In: J.B. Rose and B. Jiménez-Cisneros, (eds). Global Water Pathogens Project. http://www. waterpathogens.org (C. Haas, J.R. Mihelcic and M.E. Verbyla (eds) Part 4 Management Of Risk from Excreta and Wastewater), 2018 http://www. waterpathogens.org/book/membrane-bioreactors Michigan State University, E. Lansing, MI, UNESCO. Acknowledgements: K.R.L. You

13. Hai Fl, Riley T, Shawkat S, Magram SF, Yamamoto K (2014) Removal of pathogens by membrane bioreactors: a review of the mechanisms influencing factors and reduction in chemical disinfectant dosing. Water 6:3603-3630

14. Kauser I, Ciesielski M, Poretsky RS (2019) Ultraviolet disinfection impacts the microbial community composition and function of treated wastewater effluent and the receiving urban river. PerrJ 7:e7455

15. De Luca G, Sacchetti R, Zanetti F, Leoni E (2008) Comparative study on the efficiency of peracetic acid and chlorine dioxide at low doses in the disinfection of urban wastewaters. Ann Agric Environ Med 15:217-224

16. Alcalde L, Folch M, Tapias JC, Martínez F, Enguídanos S, Bernácer I (2008) Secondary effluent reclamation: combination of pre-treatment and disinfection technologies. Water Sci Technol 57:1963-1968

17. International Standards Organisation (ISO). 2013. Water quality_enumeration of Clostridium Perfringens - method using membrane filtration. ISO 14189,Geneva, Switzerland

18. Bonetta S, Borelli E, Bonetta S, Conio O, Palumbo F, Carraro E (2011) Development of a PCR protocol for the detection of Escherichia coli O157:H7 and Salmonella spp. in surface water. Environ Monit Assess 177:493-503

19. Bonetta Sa, Pignata C, Bonetta Si, Meucci L, Giacosa D, Marino E, Gorrasi I, Gilli G, Carraro E (2018) Effectiveness of a neutral electrolysed oxidising water (NEOW) device in reducing Legionella pneumophila in a water distribution system: a comparison between culture, qPCR and PMA-qPCR detection methods. Chemosphere 210:550-556

20. International Standards Organisation (ISO) (2017) Water quality-enumeration of Legionella. Switzerland, Geneva

21. International Standards Organisation (ISO). 2002. Water quality—determination of chemical oxygen demand index (ST-COD) - Small scale sealed tube method. ISO 15705, Geneva, Switzerland

22. International Standards Organisation (ISO). 2003. Water quality-determination of biochemical oxygen demand after $n$ days (BODn). - part 1 : dilution and seeding method with allylthiourea addition. ISO 1585-1, Geneva, Switzerland

23. IRSA-CNR APAT, 2003, Metodi analitici per le acque - Parametri chimico fisici, 1, Section 2000

24. Bolzonella D, Fatone F, di Fabio S, Cecchi F (2010) Application of membrane bioreactor technology for wastewater treatment and reuse in the Mediterranean region: focusing on removal efficiency of non-conventional pollutants. J Environ Manag 91:2424-2431

25. De Luca G, Sacchetti R, Leoni E, Zanetti F (2013) Removal of indicator bacteriophages from municipal wastewater by a full-scale membrane bioreactor and a conventional activated sludge process: implications to water reuse. Bioresour Technol 129:526-531

26. Marti E, Monclús H, Jofre J, Rodriguez-Roda I, Comas J, Balcázar JL (2011) Removal of microbial indicators from municipal wastewater by a membrane bioreactor (MBR). Bioresour Technol 102:5004-5009

27. Zanetti F, De Luca G, Sacchetti R (2010) Performance of a full-scale membrane bioreactor system in treating municipal wastewater for reuse purposes. Bioresour Technol 101:3768-3771

28. Azis K, Vardalachakis C, Ntougias S, Melidis P (2017) Microbiological and physicochemical evaluation of the effluent quality in a membrane bioreactor system to meet the legislative limits for wastewater reuse. Water Sci Technol 76:1796-1804
29. Stampi S, De Luca G, Onorato M, Ambrogiani F, Zanetti F (2002) Peracetic acid as an alternative wastewater disinfectant to chlorine dioxide. J Appl Microbiol 2002(93):725-731

30. Decreto Ministeriale 12 giugno 2003, n. 185. Regolamento recante norme tecniche per il riutilizzo delle acque reflue

31. C. Cataldo, Briancesco R., Bonadonna L. (2001) Acque di riuso: aspetti sanitari e tecnici correlati alla presenza di patogeni enterici. Istituto Superiore di Sanità Rapporti ISTISAN 01/34 ISSN: 1123-3117

32. Bonetta S, Pignata C, Bonetta S, Amagliani G, Brandi G, Gilli G, Carraro E (2021) Comparison of UV, peracetic acid and sodium hypochlorite treatment in the disinfection of urban wastewater. Pathogens 10:182

33. Touron A, Berthe T, Pawlak B, Petit F (2025) Detection of Salmonella in environmental water and sediment by a nested-multiplex polymerase chain reaction assay. Res Microbiol 156:541-553

34. Li D, Zeng S, Gu AZ, He M, Shi H (2013) Inactivation, reactivation and regrowth of indigenous bacteria in reclaimed water after chlorine disinfection of a municipal wastewater treatment plant. J Environ Sci 25:1319-1325

35. Abulreesh HH, Paget TA, Goulder R (2006) Campylobacter in waterfowl and aquatic environments: incidence and methods of detection. Environ Sci Technol 40:7122-7131

36. Shannon KE, Lee DY, Beaudette LA (2007) Application of real-time quantitative PCR for the detection of selected bacterial pathogens during municipal wastewater treatment. Sci Total Environ 382:121-129

37. Mosteo R, Ormad MP, Goñi P, Rodríguez-Chueca J, García A, Clavel A (2013) Identification of pathogen bacteria and protozoa in treated urban wastewaters discharged in the Ebro River (Spain): water reuse possibilities. Water Sci Technol 68:575-583

38. Brissaud F, Blin E, Hemous S, Garrelly L (2008) Water reuse for urban landscape irrigation: aspersion and health related regulations. Water Sci Technol 57:781-787

39. Kulkarni P, Olson ND, Paulson JN, Pop M, Maddox C, Claye E, Rosenberg Goldstein RE, Sharma M, Gibbs SG, Mongodin EF, Sapkota AR (2018) Conventional wastewater treatment and reuse site practices modify bacterial community structure but do not eliminate some opportunistic pathogens in reclaimed water. Sci Total Environ 639:1 126-1137

40. Lund V, Fonahn W, Pettersen JE, Caugant DA, Ask E, Nysaeter A (2014) Detection of Legionella by cultivation and quantitative real-time polymerase chain reaction in biological waste water treatment plants in Norway. $J$ Water Health 12:543-554

41. Mailler R, Meche P, Rocher V (2021) What removals of pathogen indicators can be expected within large-scale wastewater treatment facilities in the context of wastewater reuse in Paris conurbation? Water Sci Technol 83:781-791

\section{Publisher's Note}

Springer Nature remains neutral with regard to jurisdictional claims in published maps and institutional affiliations.

\section{Submit your manuscript to a SpringerOpen ${ }^{\odot}$ journal and benefit from:}

- Convenient online submission

- Rigorous peer review

- Open access: articles freely available online

- High visibility within the field

- Retaining the copyright to your article

Submit your next manuscript at springeropen.com 